\title{
Sequential toxicity identification evaluation (TIE) for characterizing toxicity of Venice Lagoon sediments: Comparison of two different approaches is
}

\author{
Marco Picone ${ }^{\mathrm{a}, *}$, Martina Bergamin ${ }^{\mathrm{a}}$, Elisa Volpato ${ }^{\mathrm{a}}$, Eugenia Delaney ${ }^{\mathrm{a}}$, Clara Turetta ${ }^{\mathrm{b}}$, \\ Martina Ranaldo ${ }^{c}$, Gabriele Capodaglio ${ }^{\mathrm{b}, \mathrm{c}}$, Cristina Nasci ${ }^{\mathrm{a}}$ \\ ${ }^{\text {a }}$ Thetis S.p.A., Castello 2737/f, I-30122 Venice, Italy \\ b Institute for the Dinamic of Environmental Processes, IDPA-CNR, Dorsoduro 2137, I-30123 Venice, Italy \\ ' Department of Environmental Sciences, Ca' Foscari University of Venice, Dorsoduro 2137, I-30123 Venice, Italy
}

\section{A R T I C L E I N F O}

\section{Article history:}

Received 24 April 2008

Accepted 1 June 2008

Available online 21 August 2008

Keywords:

Toxicity identification evaluation

Pore water

Bivalves

\begin{abstract}
A B S T R A C T
A toxicity identification evaluation phase-I (TIE-1) procedure was carried out on five pore water samples extracted from sediments of the Venice Lagoon previously investigated to assess both chemical contamination and toxic effects on the biota. Two different sequential TIE procedures were tested. A first sequence (TIE-1) provided for adding $\mathrm{Na}_{2} \mathrm{~S}_{2} \mathrm{O}_{3}$, adding Na-EDTA, filtering, elution through a C18-SPE column and removing ammonia using the macroalgae Ulva rigida Agardh 1823, while a second procedure (TIE-2) was set up using $U$. rigida treatment for ammonia removal as first step, keeping unchanged the sequence of the other manipulations. Two different exposure time to the macroalgae were tested (3-h and 15-h). Sperm-cell toxicity test with the echinoid Paracentrotus lividus and embryotoxicity tests with the bivalves Mytilus galloprovincialis and Crassostrea gigas were performed on pore-water samples to assess the effect of the sequential treatments on the overall toxicity. The results confirmed that ammonia contribution to toxicity is strong in most of the samples and that metals, specially $\mathrm{Cu}$, are of concern at least in three sites. The TIE-2 procedure provided more reliable results for the samples characterized by high ammonia contribution to the overall toxicity, whereas the results of TIE-1 and TIE-2 were equivalent for the samples where ammonia contribution was not prevailing. Chemical analyses and test results showed that a 3-h $U$. rigida exposure is suitable to remove ammonia toxicity minimizing potential metal up-take.
\end{abstract}

(c) 2008 Elsevier Inc. All rights reserved.

\section{Introduction}

The Venice Lagoon is a shallow water and high productivity environment characterized by strong gradients in sediment contamination and toxicity towards the biota. In shallows and channels located near the Industrial Area of Porto Marghera and the city of Venice, the concentrations of metals and organic micropollutants are often several times higher than in the other basins of the Lagoon and exceed the sediment quality guidelines for several contaminants. Toxicity tests performed on sediments, elutriates, and pore waters sampled in this area highlighted the occurrence of both acute and sub-chronic toxicity (Volpi Ghirardini et al., 2005a; Picone, 2006; Losso et al., 2007; Picone et al., 2008), but the main chemicals affecting toxicity were not

\footnotetext{
All the assays carried out with oysters, mussel, and sea-urchins during the experimental period were performed in accordance with national and institutional guidelines for the protection of wildlife animal welfare.

* Corresponding author. Fax: +390415210292.

E-mail address: marco.picone@thetis.it (M. Picone).
}

established and there is still uncertainty and disagreement about the contribution of ammonia to the measured effects.

With the aim to identify the toxicants eliciting toxicity and to clarify the role of ammonia as potential toxicant in the area surrounding the industrial area, a phase-I toxicity identification evaluation (TIE) was then carried out on five previously investigated sites.

Toxicity characterization of the pore water was performed following two step-wise sequential approaches, both based on the procedure originally developed by the US Naval Facilities Engineering Service Center (NFESC, 2003). The sequential approach was preferred to the traditional "in parallel" procedure because it allows the minimization of the risk of the "masking effect", occurring when the ability to distinguish the effects of one class of contaminants is impeded by the remaining contaminants (NFESC, 2003). Moreover, the sequential approach is expected to yield more reliable interpretations of the results when multiple classes of contaminants are of concern (NFESC, 2003).

A first procedure (TIE-1) was carried out following step-bystep the model developed by NFESC and lies, respectively, in adding $\mathrm{Na}_{2} \mathrm{~S}_{2} \mathrm{O}_{3}$ solution (STS), adding Na-EDTA solution, filtering 
pore water, elution through a $\mathrm{C}_{18}$-SPE column, and finally treating pore water with Ulva rigida Agardh, 1823. A second procedure (TIE-2) was set up using the exposure to $U$. rigida as first treatment of the sequence and keeping unaltered the series of the other treatments. The use of ammonia removal as first treatment was suggested by the need to minimize the masking role that ammonia could play when its concentrations are high enough to greatly affect test results, as often occurs in the sites close to the industrial area. Indeed, when the samples are characterized by high concentration of ammonia, the removal of toxicity obtained with STS, EDTA, filtration, and elution in TIE-1 can have little to no-effect on toxicity test results, due to the persisting effects of ammonia.

In order to verify which approach is the more reliable for application in the Lagoon of Venice, the performances of both TIEs were evaluated testing untreated and treated pore-water samples with the sperm-cell test with the Mediterranean sea-urchin Paracentrotus lividus (acute toxicity test) and the embryo-toxicity tests with the bivalves Mytilus galloprovincialis or Crassostrea gigas (short-chronic toxicity tests).

Ammonia removal rate by $U$. rigida during the exposure was evaluated measuring ammonia concentrations in the untreated samples and after the Ulva treatment during TIE-1 experiment, while the possible up-take of metals was verified in TIE-2, by comparing metal concentrations in the pore water before and after the exposure to the macro-algae.

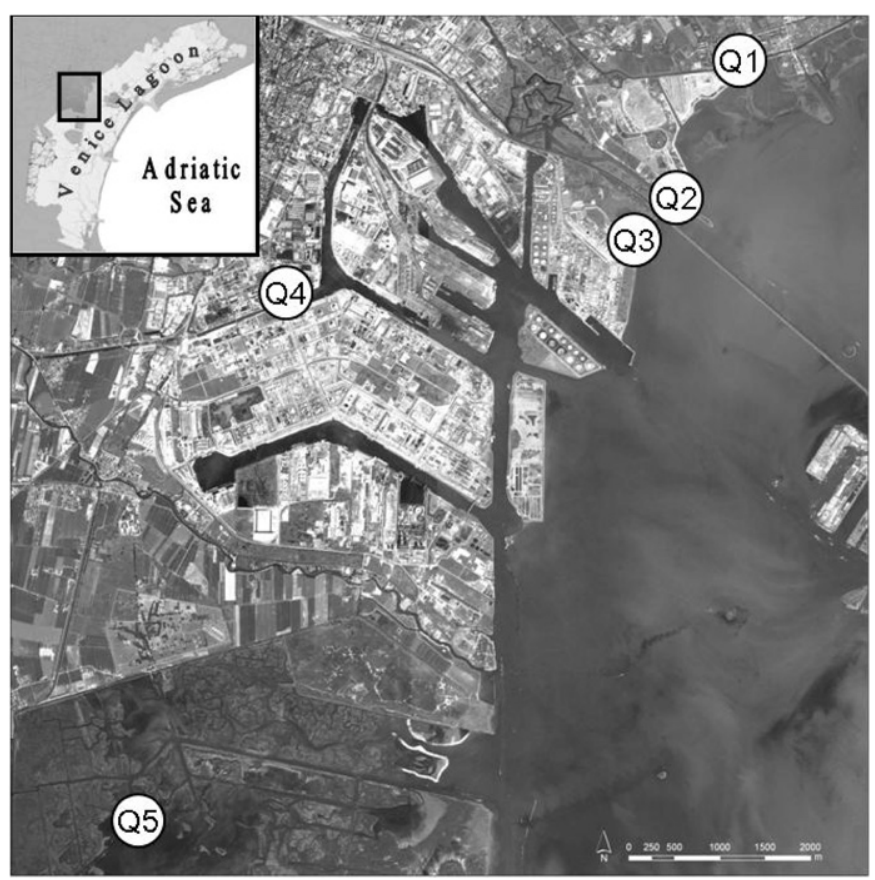

Fig. 1. Sampling sites location.

\section{Materials and methods}

\subsection{Site selection and sediment sampling}

Five sites (see Fig. 1) were chosen on the basis of previous data concerning chemical contaminantion and toxicity. The criteria selected to verify site eligibility for TIE application were (1) previously demonstrated acute and/or sub-chronic toxicity, (2) occurrence of contaminants of potential concern above benchmarks (ERL/ERM), and (3) possible presence of confounding factors, mainly ammonia. Summary of site selection criteria is reported in Table 1.

Surface sediments $(0-10 \mathrm{~cm})$ were sampled in January 2007 using a $10-\mathrm{cm}$ diameter Plexiglas ${ }^{\mathbb{R}}$ corer and preserved in 2-L glass container filled without leaving headspace until arrival in the laboratory, where they were kept overnight at $4{ }^{\circ} \mathrm{C}$ before starting pore-water extraction; $8 \mathrm{~L}$ of sediment were sampled at each site.

\subsection{Pore-water extraction and TIE manipulations}

Pore water was extracted by centrifuging the bulk sediments at $13,000 \mathrm{~g}$ for $30 \mathrm{~min}$ at $4{ }^{\circ} \mathrm{C}$ using $250-\mathrm{mL}$ polycarbonate bottles. Pore-water samples were frozen immediately after centrifugation and thawed at room temperature the night before starting TIE; sediment handling prior to pore-water extraction and all the TIE manipulations were performed under nitrogen atmosphere to minimize artifacts due to exposure to oxygen.

The TIE-1 step-wise procedure is reported in Fig. 2. All the treatments were consistent with EPA procedures (US EPA, 1991, 1996), whereas U. rigida addition was carried out following Ho et al. (1999) with minor modification. Briefly, after preserving aliquots of untreated sample for chemical analysis (ammonia and metals) and a baseline toxicity test, the $\mathrm{Na}_{2} \mathrm{~S}_{2} \mathrm{O}_{3}$ (STS) solution $(0.095 \mathrm{M})$ was added at a rate of $3.4 \mu \mathrm{L} / \mathrm{mL}$ of sample. This treatment is expected to remove the toxicity due to a subset of cationic metals $(\mathrm{Cd}, \mathrm{Cu}, \mathrm{Ag}$, and $\mathrm{Hg}$ ) and some oxidant agents (US EPA, 1996; NFESC, 2003). After STS addition, 1-h was allowed to pass before adding Na-EDTA solution $(0.075 \mathrm{M})$ at a rate of $2.4 \mu \mathrm{L} / \mathrm{mL}$ of sample. The pore water was then allowed to interact with EDTA for at least 2-h to remove the toxicity associated with the residual divalent cationic metals; subsequently the samples were filtered through a glass-fiber filter with porosity $0.45 \mu \mathrm{m}$ to eliminate the particulate matter (PM) that could cause toxicity (US EPA, 1996; NFESC, 2003) or clog the solid phase extraction column. Elution was performed at a rate not exceeding $10 \mathrm{~mL} / \mathrm{min}$ using disposable C18-SPE columns (Isolute, International Sorbent Technology Ltd., UK) to remove the toxicity associated with

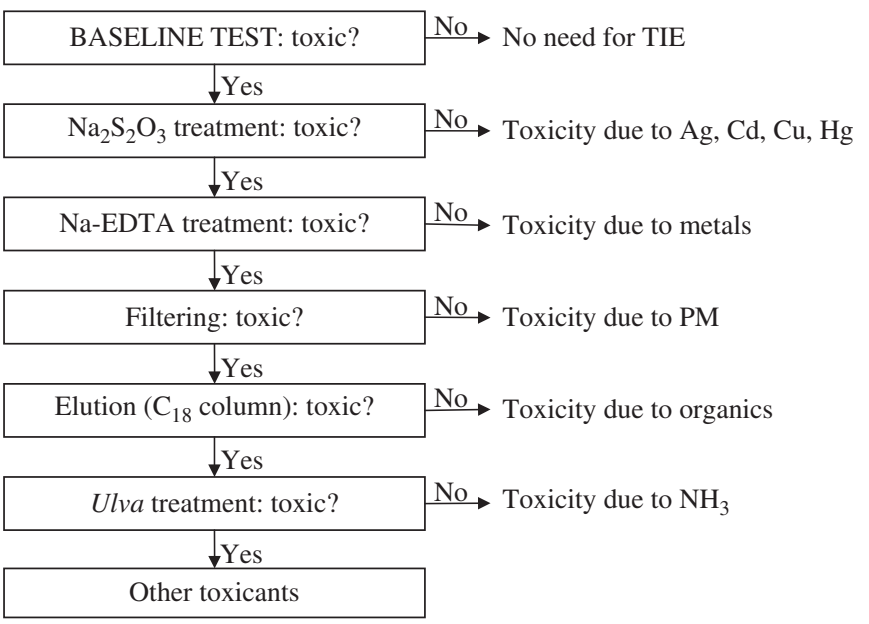

Fig. 2. Sequential procedure for TIE-1 (NFESC, 2003).

Table 1

Summary of site selection criteria for TIE applicability

\begin{tabular}{|c|c|c|c|c|}
\hline \multicolumn{2}{|c|}{ Sampling site } & \multirow[t]{2}{*}{ COPCs above ERL/ERM } & \multirow[t]{2}{*}{ Previous toxicity } & \multirow[t]{2}{*}{ Confounding factors } \\
\hline Label & Area & & & \\
\hline Q1 & Osellino & n.a. & Highly toxic (sea-urchins and bivalves embryos) & Ammonia \\
\hline Q2 & San Giuliano & As, $\mathrm{Cd}, \mathrm{Cu}, \mathrm{Hg}^{*}, \mathrm{~Pb}, \mathrm{Zn}^{*}$ & Toxic (amphipods and sea-urchin embryos) & Ammonia \\
\hline Q3 & Pili & As, $\mathrm{Cd}, \mathrm{Cu}, \mathrm{Hg}^{*}, \mathrm{Ni}, \mathrm{Pb}, \mathrm{Zn}^{*}$ & Toxic (amphipods and sea-urchins embryos) & Ammonia \\
\hline Q4 & Darsena della Rana & As, $\mathrm{Cd}, \mathrm{Cr}, \mathrm{Cu}, \mathrm{Hg}^{*}, \mathrm{Ni}^{*}, \mathrm{~Pb}, \mathrm{Zn}$ & Highly toxic (sea-urchins and bivalves), toxic (amphipods) & Ammonia \\
\hline Q5 & Lago dei Teneri & As, $\mathrm{Cd}, \mathrm{Cu}, \mathrm{Hg}, \mathrm{Ni}, \mathrm{Zn}$, phenanthrene & Highly toxic (sea-urchin embryos) & Ammonia (possible) \\
\hline
\end{tabular}

*Indicates COPCs above ERM. 


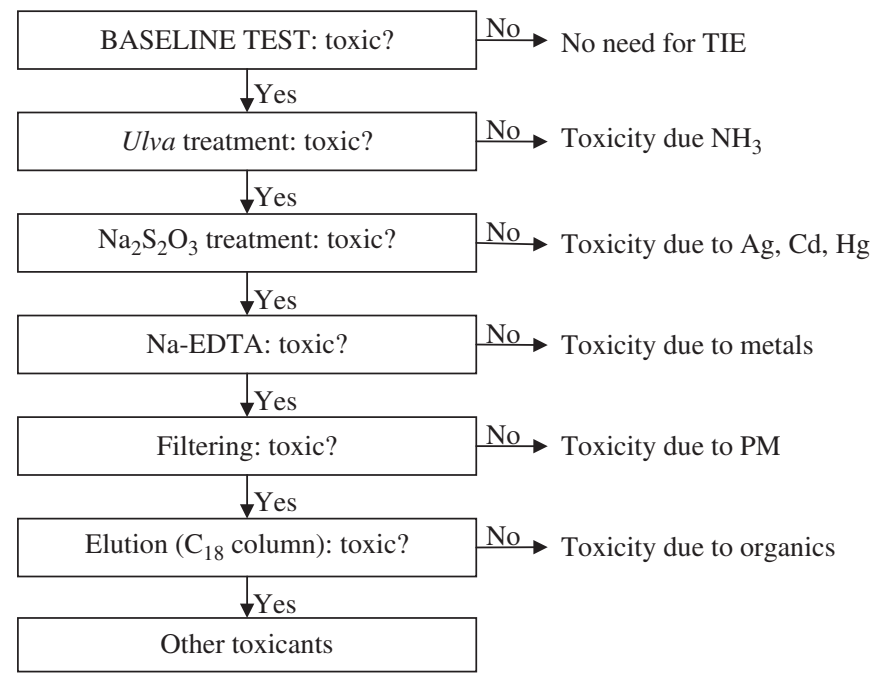

Fig. 3. Sequential procedure for TIE-2.

non-polar organics (benzenes, PCBs, and PAHs) (US EPA, 1996; Ho et al., 1997). $U$. rigida treatment was carried out adding $1 \mathrm{~g}$ of thallus to each $15 \mathrm{~mL}$ of sample; the exposure was performed in $1 \mathrm{~L}$ glass beaker, at $18^{\circ} \mathrm{C}$ and under constant illumination for 3-h. Exposure time was prolonged to 15 -h for those sites where ammonia concentrations were expected to be higher. Before testing, Ulva was kept for 2-d in aquaria filled with artificial seawater (ASTM, 2004) under 14:10 light:dark conditions at $18{ }^{\circ} \mathrm{C}$; before starting TIE, the thallus of Ulva was carefully rinsed with artificial sea water to remove particles and/or debris and then blotted on absorbent paper to remove excess water.

The TIE- 2 procedure (Fig. 3 ) is largely the same as TIE- 1 procedure, but in contrast the 3-h $U$. rigida treatment for ammonia removal was set up as the first manipulation.

\subsection{Chemical analyses}

Ammonia in the pore waters was measured in the untreated samples, after the 3-h Ulva exposure and (for samples Q1, Q2, and Q5) after the 15-h Ulva exposure too. The analyses were carried out using the blue indophenols methods following the standard procedure APAT-CNR-IRSA, Man. 29/2003, Method no. 4030 A1.

Trace metal analyses (As, $\mathrm{Cd}, \mathrm{Co}, \mathrm{Cu}, \mathrm{Fe}, \mathrm{Mo}, \mathrm{Ni}, \mathrm{Pb}, \mathrm{Sb}, \mathrm{Ti}$, and $\mathrm{Zn}$ ) were performed by ICP-QMS (Agilent 7500) following a methodology previously reported (Turetta et al., 2004). The instrument was installed in a dedicated laboratory with sample introduction area protected by a laminar flow cabinet. Intensity was optimized daily using a tuning solution of $\mathrm{In} 1 \mathrm{ng} / \mathrm{mL}$ in ultrapure water. Mass calibration was performed before beginning the analyses using a solution containing elements with $\mathrm{m} / \mathrm{z}$ values covering the whole mass range of interest.

A direct sample introduction system was used to minimize the formation of oxides; it was constituted by a $\mu$-flow nebulizer coupled with a desolvation unit (Aridus, Cetac Technologies, Omaha, NE, USA). Each sample was 10 -fold diluted using ultrapure water Purelab-Ultra system (ELGAVivendi Water Systems, Bucks, UK), and acidified with UPA grade $\mathrm{HNO}_{3}(1: 10 \mathrm{v} / \mathrm{v})$; to correct changes of instrument sensitivity during the analyses, an internal standard solution of In, Sc, Y, and $\mathrm{W}(1 \mathrm{ng} / \mathrm{mL})$ was added. The accuracy of the analyses was measured using a certified reference material (CRM-CASS-4). Measured values resulted in good agreement with certified values, being the difference between measured and certified values less than $5 \%$. For Sb, whose concentration is not certified, a mean values of $0.240 \mathrm{ng} / \mathrm{mL}$ was obtained, which agree with expected values for coastal seawater.

The quantification of trace metals was carried out by a matched calibration method. Five aliquots of CASS-4, handled as just described for the samples, were spiked with a multi-element standard solution.

\subsection{Toxicity testing and data analyses}

Adult sea-urchins were sampled in the Tyrrhenian Sea by scuba divers and transported immediately to the laboratory where they were gradually acclimatized to testing conditions $\left(18^{\circ} \mathrm{C}, \mathrm{S}=35 \mathrm{psu}\right.$ ) for at least 1 week. Mussels were sampled in the Adriatic Sea and kept in the laboratory at $18^{\circ} \mathrm{C}$ and $S=35$ psu for at least 1 week before testing. Conditioned oysters were purchased from Guernsey Sea Farms (Vale, Guernsey, UK) and used immediately after their arrival in the laboratory.
Sperm-cell test with $P$. lividus was performed only for TIE-1 samples, following Volpi Ghirardini and Arizzi Novelli (2001). Embryo-larval development tests with the bivalves were performed according to ASTM (2004) standard method; M. galloprovincialis was used only for TIE-1 on pore water from sites Q1 and Q2, whereas $C$. gigas was used for all the remaining samples.

All tests were performed in triplicate using at least six concentrations of pore water $(100 \%, 50 \%, 25 \%, 12 \%, 6 \%$, and 3\%). The artificial seawater (ASTM, 2004) used as dilution water was treated exactly as the samples, in order to avoid misleading results due to dilution effect. Toxicity tests were performed within 24 -h after the beginning of TIE manipulations and within 2 weeks from sediment sampling.

According to the $\mathrm{QA} / \mathrm{QC}$ programme, negative controls with artificial sea water (treated as the samples) and positive control with the reference toxicant $(\mathrm{Cu})$ were performed simultaneously with tests on pore water.

Tests results were expressed in toxicity units (TU) calculated as $\mathrm{TU}_{50}=$ $100 / \mathrm{EC}_{50}$ (where $\mathrm{EC}_{50}=$ effective concentration 50 ) for those sample/treatments exhibiting more than $50 \%$ of effect in the undiluted sample or as $\mathrm{TU}_{50}=$ $(100-S) / 50$ for the samples not reaching $50 \%$ of effect in the undiluted sample, where $S$ represents the percentage of success of the test (i.e. percentage of normally developed larvae) normalized to the control. $\mathrm{EC}_{50}$ were calculated using the trimmed Spearman-Karber method (US EPA (United States Environmental Protection Agency), 2002). One-way analysis of variance and Fisher post-hoc test on log-transformed data were used to check for differences among treatments and to identify the treatments significantly affecting test responses. KolmogorovSmirnov and Bartlett's tests were used to check for normality and variance homogeneity, respectively. All statistical analyses were performed using StatSoft Statistica v 6.0 .

\section{Results}

\section{1. $Q A / Q C$}

The percentage of fertilized eggs and normally developed larvae in the negative controls was always $>70 \%$; the $\mathrm{EC}_{50}$ calculated for the tests with the reference toxicant (37 and $33 \mu \mathrm{g} / \mathrm{L}$ of $\mathrm{Cu}$ for sea-urchin sperm cell, 12.1 and $11.6 \mu \mathrm{g} / \mathrm{L}$ of $\mathrm{Cu}$, respectively, for embryo-toxicity with mussels and oysters) were always within the control chart limits (24-75, 3-27, and 2-16 $\mu \mathrm{g} / \mathrm{L}$ of $\mathrm{Cu}$, respectively, for sperm-cell with $P$. lividus and embryotoxicity with $M$. galloprovincialis and $C$. gigas) (Picone and Bergamin, unpublished data).

\subsection{TIE-1}

The data obtained with the sperm-cell test are reported in Table 2. Only site Q1 showed acute toxicity towards the gametes of $P$. lividus, with a percentage of fertilized eggs $<50 \%$. Only the EDTA treatment and the 3-h Ulva exposure reduced significantly the effect, highlighting a main contribution of divalent cationic metals and ammonia to the toxicity. The other pore-water samples showed minor effects and the characterization of the toxicant is not reliable; however, at the end of the step-wise procedure all the samples showed a percentage of fertilized eggs higher than $75 \%$, evidencing an overall reduction of the effects.

Results of the embryo-toxicity tests with bivalves are reported graphically in Fig. 4 and the percentages of toxicity reduction

Table 2

Results of sperm-cell test on TIE-1 samples

\begin{tabular}{|c|c|c|c|c|c|}
\hline \multirow[t]{2}{*}{ Treatment } & \multicolumn{5}{|l|}{ Site } \\
\hline & Q1 & Q2 & Q3 & Q4 & Q5 \\
\hline Baseline & $49 \pm 7.1$ & $67 \pm 4.3$ & $65 \pm 3.8$ & $71 \pm 6.3$ & $65 \pm 0.8$ \\
\hline STS & $41 \pm 2.5$ & $61 \pm 5.4$ & $64 \pm 3.7$ & $60 \pm 1.9$ & $55 \pm 2.5$ \\
\hline EDTA & $62 \pm 4.4$ & $73 \pm 3.0$ & $65 \pm 1.0$ & $70 \pm 3.4$ & $81 \pm 2.4$ \\
\hline Filtration & $62 \pm 2.1$ & $41 \pm 14.0$ & $71 \pm 4.7$ & $78 \pm 6.3$ & $69 \pm 4.4$ \\
\hline $\mathrm{C}-18$ & $69 \pm 8.9$ & $71 \pm 4.7$ & $71 \pm 3.5$ & $80 \pm 3.5$ & $80 \pm 3.0$ \\
\hline Ulva $3 \mathrm{~h}$ & $98 \pm 6.0$ & $93 \pm 2.5$ & $72 \pm 4.7$ & $88 \pm 7.4$ & $85 \pm 2.0$ \\
\hline Ulva $15 \mathrm{~h}$ & $90 \pm 9.6$ & $94 \pm 8.0$ & $79 \pm 3.3$ & $85 \pm 5.3$ & $76 \pm 9.1$ \\
\hline
\end{tabular}

Data are reported as percentage of fertilized eggs normalized to the control ( $\mathrm{S} \%$ ). 

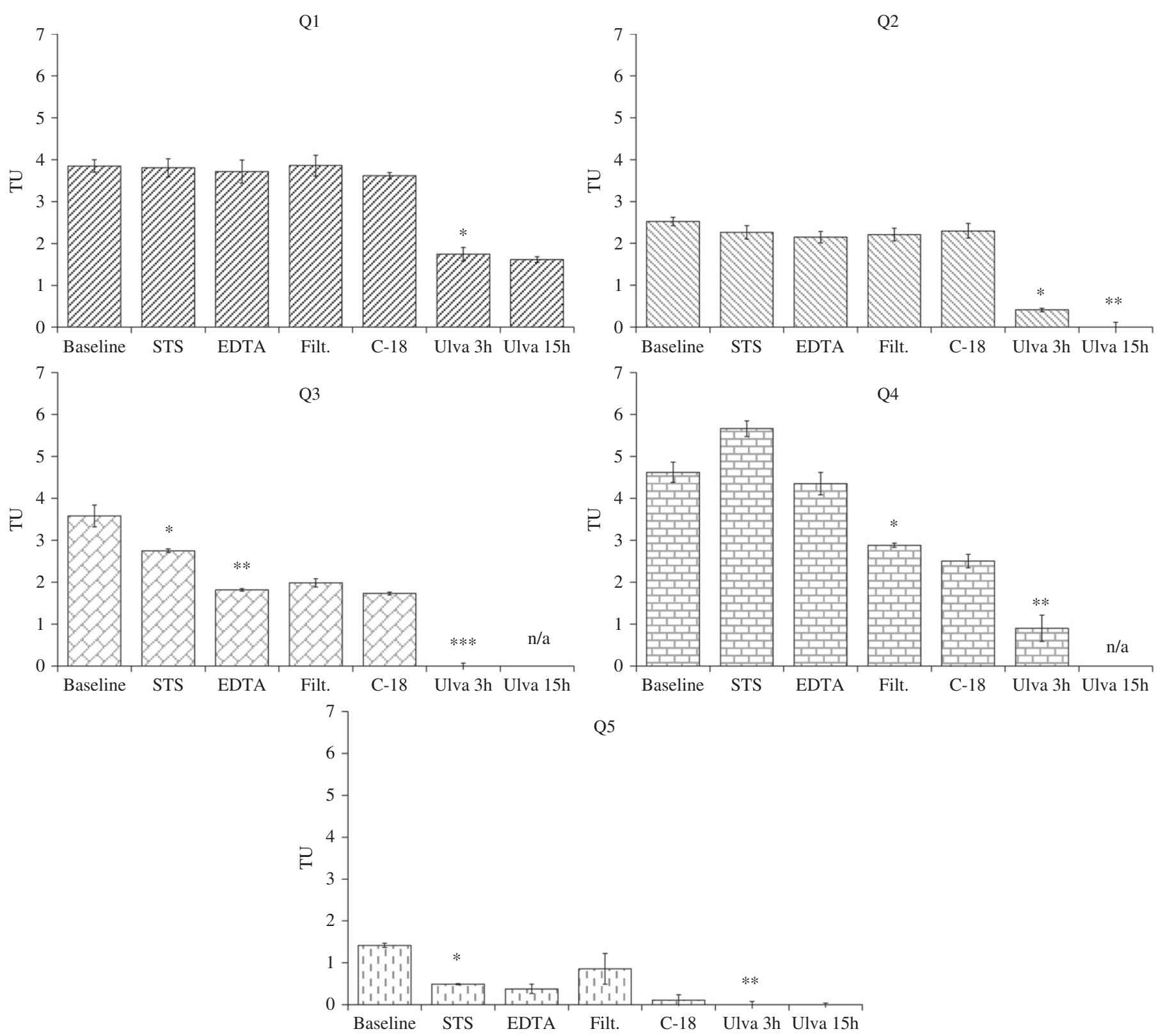

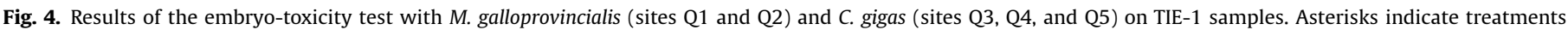
significantly different $(p<0.05)$ from the previous after one-way ANOVA and post-hoc test. N/a $=$ data not available.

obtained after each treatment are listed in Table 3. All samples but Q5 showed high toxicity towards embryos (TU $>2$ ). On sites Q1 and Q2, only the Ulva treatments were able to remove toxicity towards M. galloprovincialis (TU reduced from 3.85 to 1.75 and from 2.52 to 0.42 in Q1 and Q2, respectively), suggesting ammonia as a unique toxicant of concern; in Q1 residual toxicity remained $(\mathrm{TU}=1.59)$ at the end of the TIE, whereas in Q2 the toxicity was completely removed after the 15 -h Ulva treatment.

In site Q3, the presence of multiple classes of toxicants was highlighted; the toxicity was indeed significantly reduced by STS addition (TU from 3.58 to 2.75 ), EDTA addition (TU from 2.75 to 1.82), and 3-h Ulva exposure; at the end of the TIE-1 procedure the toxicity was absent (TU from 1.99 to 0 after 3-h Ulva exposure).

In site Q4 STS addition produced an unexpected increase of the toxicity ( $\mathrm{TU}=5.66)$ as compared with baseline test $(\mathrm{TU}=4.62)$. All the subsequent manipulation provided significant reduction of the toxicity: the EDTA treatment lowered the toxicity at levels similar to those measured in the baseline test ( $T U=4.36)$, while filtration and 3-h Ulva treatments reduced significantly the effects on $C$. gigas embryos up to $\mathrm{TU}=0.91$. Residual toxicity remained after treatment $U$. rigida. Both for $\mathrm{Q} 3$ and $\mathrm{Q} 4$, the 15-h Ulva treatment was not performed.

Pore water from site Q5 was the less toxic and the only one with baseline toxicity less than $2 \mathrm{TU}(\mathrm{TU}=1.41)$; STS addition and 3-h Ulva exposure reduced significantly the toxicity, even if the obtained toxicity reduction was very low.

\subsection{TIE-2}

The histograms in Fig. 5 highlight the treatments statistically able to reduce the effects toward oyster embryos, while Table 4 shows the percentage of toxicity reduction obtained after each treatment. In site Q1, the 3-h Ulva treatment reduced the toxicity 
from TU 6.30 to TU 1.57 and $\mathrm{C}_{18}$ SPE treatment produced a weak but significant decrease of the toxicity (up to $\mathrm{TU}=0.79$ ). However, as in TIE-1, at the end of the procedure the sample was still slightly toxic.

Table 3

Summary of toxicity removed by each treatment in TIE-1

\begin{tabular}{lrrlllr}
\hline Treatment & \multicolumn{2}{l}{ Site } & & & \\
\cline { 2 - 6 } & Q1 & Q2 & Q3 & Q4 & Q5 \\
\hline STS & 1 & 10 & 23 & -23 & 65 \\
EDTA & 2 & 5 & 26 & 28 & 8 \\
Filtration & 0 & 0 & 0 & 32 & -34 \\
C-18 & 3 & 0 & 2 & 8 & 53 \\
3h-Ulva & 49 & 69 & 48 & 35 & 8 \\
15h-Ulva & 3 & 17 & n.a. & n.a. & 4 \\
Total toxicity removed by TIE-1 & 58 & 100 & 100 & 80 & 100
\end{tabular}

All data are expressed in terms of \% of initial toxicity. Negative numbers indicate significant increase of effect.
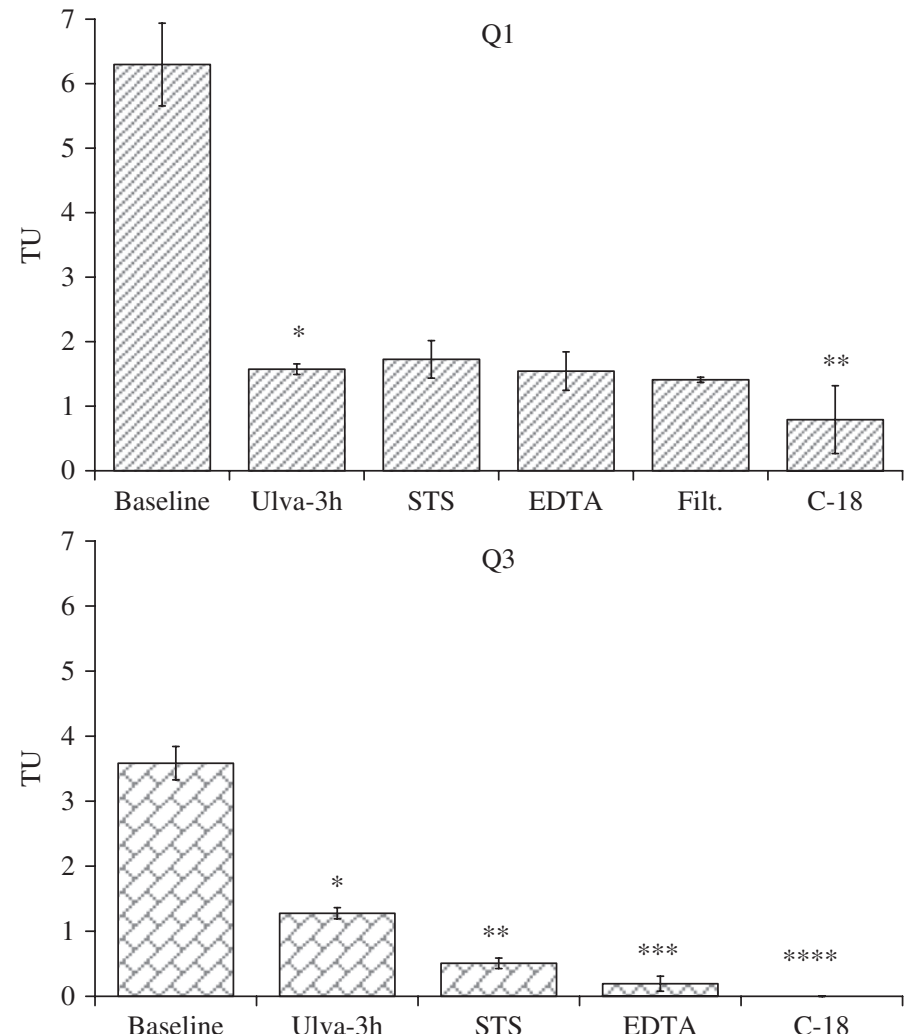

Q3
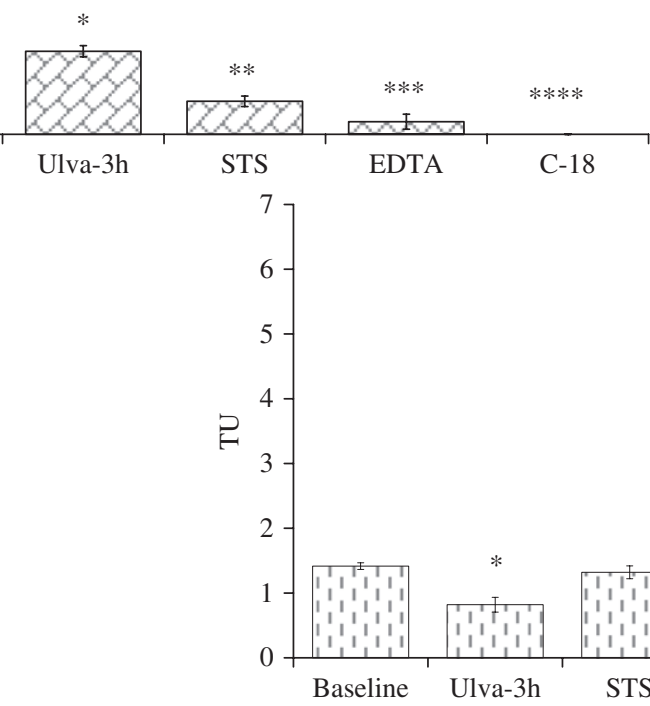

Pore water from site Q2 was non-toxic at the end of the sequence; the 3-h Ulva treatment provided a marked reduction of the toxicity (from TU $=3.49$ to 1.26 ) and the residual effect measured after EDTA addition $(\mathrm{TU}=0.36)$ was completely

Table 4

Summary of toxicity removed by each treatment in TIE-2

\begin{tabular}{lrrrrr}
\hline Treatment & \multicolumn{2}{l}{ Site } & & & \\
\cline { 2 - 6 } & Q1 & Q2 & Q3 & Q4 & Q5 \\
\hline 3h-Ulva & 75 & 64 & 64 & 39 & 42 \\
STS & 0 & 4 & 21 & 0 & -35 \\
EDTA & 0 & 22 & 9 & 27 & 69 \\
Filtration & 2 & 6 & - & 35 & 15 \\
C-18 & 10 & 4 & 5 & 0 & 9 \\
Total toxicity removed by TIE-2 & 87 & 99 & 100 & 100 & 100
\end{tabular}

All data are expressed in terms of \% of initial toxicity. Minus indicates an increase in toxicity after the treatment.
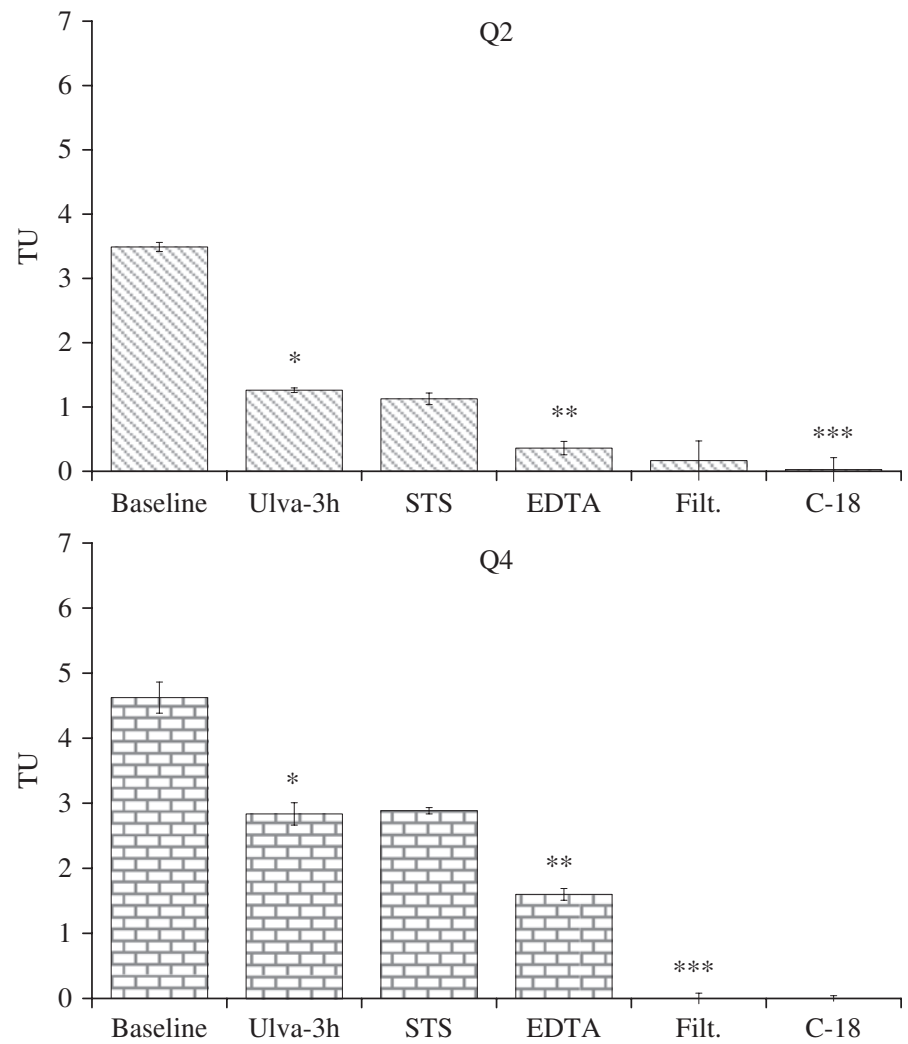

Q5 
removed by elution trough the $\mathrm{C}_{18}$ SPE column. No significant reduction was observed after STS addition and filtration.

In site Q3 exposure to Ulva and STS addition provided the higher reduction of the toxicity, from $\mathrm{TU}=3.58$, found in the baseline test, to $\mathrm{TU}=0.51$ after STS addition. Both EDTA addition and elution through $\mathrm{C}-18$ column produced a weak but significant reduction of the effects too. The larvae in all the dilutions of the filtration treatment died, so the evaluation of the effects was not possible.

In site Q4 Ulva exposure, EDTA addition and filtration significantly lowered the toxicity of the pore water; the initial toxicity of $4.62 \mathrm{TU}$ was reduced by Ulva to $2.84 \mathrm{TU}$, by EDTA to $1.60 \mathrm{TU}$ and all the residual toxicity was completely removed by filtration. Addition of STS did not alter the effect towards embryos.

As in TIE-1, the pore water from site Q5 provided the least clear results. Statistically, exposure to Ulva, EDTA and elution significantly affected toxicity, even if the differences among the treatments were minimal. STS addition caused a slight increase of the toxicity as previously observed in site Q4 after TIE-1.

\subsection{Chemical analyses}

Ammonia analyses in pore water are summarized in Table 5. $U$. rigida rapidly lowered $\mathrm{N}-\mathrm{NH}_{3}$ concentration within $3-\mathrm{h}$. The algae were able to remove from $74 \%$ up to $92 \%$ of initial $\mathrm{N}-\mathrm{NH}_{3}$ concentration in the first 3-h of exposure; the up-take rate was higher and quite constant for the more ammonia-rich sites, whereas it was quite low for site Q5, where the initial ammonia concentration was lower and probably Ulva removed ammonia within few minutes. Residual $\mathrm{N}-\mathrm{NH}_{3}$ concentration after $15-\mathrm{h}$ are very similar to the concentration measured after 3-h, confirming that Ulva up-takes most of $\mathrm{N}-\mathrm{NH}_{3}$ during the first hours of exposure.

\section{Table 5}

Results of ammonia analyses on untreated samples and after 3-h and 15-h exposure to Ulva rigida

\begin{tabular}{lrrrrr}
\hline Treatment & \multicolumn{6}{l}{ Site } & & & \\
\cline { 2 - 6 } & \multicolumn{1}{l}{ Q1 } & Q2 & Q3 & Q4 & Q5 \\
\hline Untreated sample & 8881 & 7068 & 7771 & 8585 & 2146 \\
After 3-h Ulva exposure & 914 & 766 & 644 & 1499 & 555 \\
After 15-h Ulva exposure & 918 & 714 & n/a & n/a & 759 \\
\% of reduction after 3-h & 90 & 89 & 92 & 83 & 74 \\
Ulva up-take rate $(\mu \mathrm{g} / \mathrm{Lh})$ & 2656 & 2101 & 2377 & 2362 & 530
\end{tabular}

All data are in $\mu \mathrm{g} / \mathrm{L}$ of $\mathrm{N}-\mathrm{NH}_{3}$.
The results of metal analyses on pore-water samples are reported in Table 6. Analyses were not performed on Q3 samples because the extracted pore water was not enough to perform the determination of the trace metals. For most of the investigated metals, there is no evidence of significant removal by $U$. rigida after the 3-h treatment. The concentrations of $\mathrm{Co}, \mathrm{Fe}, \mathrm{Mo}, \mathrm{Ni}, \mathrm{Sb}$, and $\mathrm{Ti}$ showed generally negligible differences among untreated and treated samples, although the iron concentration in the sample Q1 showed a significant decrease after treatment with Ulva. Cadmium and lead are characterized by higher concentrations in the treated samples than in the untreated pore water, even if only for $\mathrm{Pb}$ the increment after the exposure to the macroalgae is significant. The causes of this increment are still not clear; because the algae were carefully rinsed before the TIE, the desorption of metals from the thallus seems unlikely. Possible release of the metals by the algae through extra-cellular exudates could not be excluded, but further studies are needed to elucidate this point.

The As behaviour is more ambiguous; the data provided some evidence of active up-take by $U$. rigida for some samples during the 3-h exposure (reduction of about $40 \%$ in Q4 and Q5) while no evident trend was observed for sample Q1.

\section{Discussion}

All the sites chosen for TIE application showed relevant subchronic toxicity, while the acute effects were low or negligible in all the sites but Q1. As a consequence, only the results of the embryo-toxicity tests are eligible for evaluating the performances of the two sequential approaches proposed in this paper.

The results summarized in Figs. 4 and 5 highlight that both the TIEs were able to identify the main toxicants causing effects towards embryos development; nevertheless a site-by-site comparison shows that TIE- 1 in some cases could be affected by the "masking effect" of ammonia and then unable to detect the effects of possible "secondary" sources of toxicity.

In sites Q1 and Q2, although different species were used for TIE-1 and TIE-2 (whose sensitivity toward the main classes of toxicants is however comparable, His et al., 1999), the results highlight that ammonia is clearly the main toxicant; nevertheless, while TIE-1 identified ammonia as the sole toxicant causing effect (at least $52 \%$ and $85 \%$ of the initial toxicity, respectively), TIE-2 revealed the less discernible but significant contribution of non-polar organics in $\mathrm{Q} 1$ (10\% of the initial toxicity) and both non-polar organics and divalent cationic metals in Q2 ( $4 \%$ and $22 \%$, respectively). As a consequence, these results confirmed that keeping ammonia removal as last step in the

Table 6

Metal concentrations in untreated samples and after 3-h exposure to Ulva rigida

\begin{tabular}{|c|c|c|c|c|c|c|c|c|}
\hline & \multicolumn{2}{|l|}{ Q1 } & \multicolumn{2}{|l|}{ Q2 } & \multicolumn{2}{|l|}{ Q4 } & \multicolumn{2}{|l|}{ Q5 } \\
\hline & Untreated & After Ulva exp. & Untreated & After Ulva exp. & Untreated & After Ulva exp. & Untreated & After Ulva exp. \\
\hline As & 5.5 & 5.9 & 4.7 & 3.4 & 7.4 & 4.3 & 33.9 & 20 \\
\hline $\mathrm{Cd}$ & 0.079 & 0.068 & 0.075 & 0.195 & 0.053 & 0.131 & 0.068 & 0.163 \\
\hline Co & 1.5 & 0.8 & 0.9 & 1.4 & 0.8 & 0.8 & 1.2 & 1.4 \\
\hline $\mathrm{Cu}$ & 107 & 80 & 84 & 95 & 93 & 71 & 115 & 114 \\
\hline $\mathrm{Fe}$ & 1666 & 704 & 677 & 741 & 718 & 676 & 875 & 977 \\
\hline Mo & 5 & 5.1 & 9.7 & 14.4 & 8.2 & 5.4 & 33.5 & 34.7 \\
\hline $\mathrm{Ni}$ & 3.7 & 3.5 & 2.3 & 3.1 & 2.9 & 5.7 & 3.2 & 4.7 \\
\hline $\mathrm{Pb}$ & 1.3 & 4 & 0.3 & 0.8 & 0.3 & 1.7 & 0.2 & 4 \\
\hline $\mathrm{Sb}$ & 2 & 1.5 & 1.6 & 1.6 & 2.1 & 1.6 & 5.7 & 6.5 \\
\hline $\mathrm{Ti}$ & 0.22 & 0.23 & 0.22 & 0.24 & 0.22 & 0.23 & 0.22 & 0.23 \\
\hline $\mathrm{Zn}$ & 14.3 & 8 & 23.4 & 19.2 & 7.6 & 15.6 & 10.2 & 14 \\
\hline
\end{tabular}

Concentrations are in $\mu \mathrm{g} / \mathrm{L}$. 
sequence (as in TIE-1) can lead to underestimation of the contribution of other toxicants.

The residual toxicity in $\mathrm{Q} 1$ at the end of both the sequences could indicate the possible presence of toxicants only partially or not affected by the treatments used in TIEs. Because this site was probably influenced by agricultural runoff and located near a calcium phosphate dumping site, it cannot be excluded that toxicity could be partly related to pesticides, other polar organic contaminants and calcium phosphate.

In site Q3, there is good agreement between TIE-1 and TIE-2; both the procedures revealed the prevailing contribution of ammonia and metals to the overall effect, causing, respectively, the $97 \%$ of the effect in TIE-1 and for the $94 \%$ in TIE- 2 . Nevertheless, TIE-2 highlights a minor but significant contribution of non-polar organics.

Comparisons in site Q4 are complicated by the unexpected increase of toxicity measured after STS addition in TIE-1. The causes of this effect are still unknown; possible explanations are the reaction of STS with the chemical mixture occurring in the sample and/or the presence of contaminants in the STS solution. This latter option is, however, improbable due to the fact that the same solution was used for all the tests carried out with $C$. gigas and none of the samples showed similar trend. Despite the problem with STS in TIE-1, the results showed good agreement between the two sequences: TIE-1 evidenced toxicity due to ammonia (35\%) and PM (32\%) and similarly TIE-2 indicated an ammonia and PM contribution of about $39 \%$ and $35 \%$, respectively. The differences lie in (1) the contribution of the metals detected by TIE- 2 ( $27 \%$ of the initial toxicity) but not revealed by TIE- 1 and (2) the residual toxicity at the end of the TIE- 1 procedure $(20 \%$ of the initial toxicity). Both differences could be explained analysing the results of the STS treatment in TIE-1; even if EDTA did not reduce the toxicity as compared with the baseline test, this treatment significantly reduced the effect measured after STS addition (about 23\%), evidencing a contribution to the toxicity due to metals too, whose magnitude is very similar to that detected by TIE-2 (27\%). Moreover, the residual toxicity in TIE-1 is very similar (about $1 \mathrm{TU}$ ) to the toxicity increment measured after STS addition, suggesting that this residual toxicity could be a direct consequence of the effects caused by STS.

The toxicity measured in site Q5 was very low as compared with the other sites and lower than the limit usually recognized as thresholds for TIE application (TU $=2$, US EPA, 1996). The results obtained with the two procedures could be considered equivalent, even if analysis of variance shows more accuracy by TIE-2 in identifying possible toxicants of concern.

Chemicals analyses on elutriates confirmed that ammonia is above the toxicity threshold (no observed effect concentration) reported by ASTM (2004) of $4.7 \mathrm{mg} / \mathrm{L}$ in all samples but Q5, thus high enough to elicit toxic effects on $C$. gigas and $M$. galloprovincialis embryos. As regards the analysed metals, only $\mathrm{Cu}$ is individually of potential concern, being present in all samples at concentrations higher than our upper control chart limit for both M. galloprovincialis $(27 \mu \mathrm{g} / \mathrm{L})$ and $C$. gigas $(16 \mu \mathrm{g} / \mathrm{L})$ and above the literature reported $\mathrm{EC}_{50}$ for the bivalves (Martin et al., 1981; His et al., 1999; Volpi Ghirardini et al., 2005b). As a consequence, $\mathrm{Cu}$ is probably the main metal of concern for sites Q2, Q3, and Q4, whereas in sites Q1 and Q5 its bioavailability could be limited by the presence of natural ligands affecting metals up-take by the embryos. The reasons for the increasing $\mathrm{Pb}$ concentrations after Ulva exposure are still unknown; however, the level of $\mathrm{Pb}$ in pore water are not of concern.

Among the treatments used in the TIEs, the exposure to Ulva is clearly the less specific manipulation and its potential capacity to remove not only ammonia but metals and organics too can complicate the TIE interpretation (Ho et al., 1999; NFESC, 2003); however, the application of Ulva treatment at the beginning of the sequence significantly improves the ability of the TIE to identify the contaminants affecting test results, especially when ammonia contribution to the toxicity is clearly higher than other contaminants (as in Q1 and Q2). In these conditions, the removal of metal and organics toxicity by STS, EDTA and elution treatments had a limited effect on the overall response and sometimes is totally masked by residual ammonia toxicity. Otherwise, when ammonia is not the prevailing source of toxicity, both the sequences provide reliable and consistent characterization of the toxicant affecting the biota.

When the Ulva exposure is carried out within few hours, the potential up-take of metals and organics is very low. For metals, Ulva up-take during TIE seems not to be of concern, as up-take period for Ulva fasciata is reported to be $6-7 \mathrm{~d}$ (Rice and Lapointe, 1981; Rice, 1984), which is much larger than the 3-h exposure time applied in the present study. Moreover, the differences we measured between initial concentration and concentration after 3-h Ulva treatment were negligible for most of the metals; this is consistent with the findings of Ho et al. (1999) on Ulva lactuca (accumulation of metals less than 10\% in complex mixtures). As regards organics, Ho et al. (1999) highlighted a relatively high capacity of $U$. lactuca to remove them by seawater, most likely by adsorption to the surface of the algae rather than active uptake, but the same authors speculated that high $K_{\mathrm{ow}}$ compounds tend to remain associated with particles and dissolved organic matter. In this case, it is reasonable to expect that in pore-water testing, most of the organics contaminants could be removed by filtration rather than by Ulva. This hypothesis is consistent with the high reduction of toxicity measured in site Q4 with both the TIE procedures; in fact Q4 is located in the Industrial Area of Porto Marghera where the sediment contamination associated with organics is the highest of the whole Lagoon.

On the basis of the up-take rates calculated for the tested exposure times, in most cases a 3-h Ulva exposure is adequate to remove toxic ammonia concentrations from the pore water; in fact, within 3-h of exposure Ulva can up-take at least $7000 \mu \mathrm{g} / \mathrm{L}$ of $\mathrm{N}-\mathrm{NH}_{3}$, but we cannot exclude that the up-take rate could be higher if the algae were exposed to higher initial ammonia concentrations. Since a shorter period minimizes the possible uptake of metals and organics, the 3-h exposure is more suitable and reliable than the 15-h exposure for conducting a TIE with ammonia removal as first treatment of the sequence. Extending exposure time up to 15-h could be a good alternative for samples with relevant ammonia concentrations but possible complications in results interpretation should be taken into account.

\section{Conclusion}

Toxicity characterization of the five selected sites, both with TIE- 1 and TIE-2, highlights that in most of the pore-water samples ammonia contribution to the overall toxicity is strong. Even if is not possible to consider it as the only toxicant of concern, ammonia is clearly the primary agent or one of the key toxicants causing adverse effects toward the embryos. Regarding the other contaminants, the TIE evidenced that metals are of concern at least in three sites (Q2, Q3, and Q4); particularly, chemical analyses detected $\mathrm{Cu}$ concentrations clearly higher than the toxicity benchmarks for the larval development in all pore-water samples, evidencing a probable contribution of this metal to the overall effects in the sites where metals are of concern.

The TIE-2 sequence, with ammonia removal as first treatment, seems the more reliable procedure for those areas where ammonia concentrations are very high, because it allows the detection of the effects due to toxicants whose contribution is less 
marked than ammonia (specially organics contaminants). When ammonia and other classes of contaminants contribute about equally to the toxicity, the two approaches provided similar results. As regards ammonia removal treatment, a 3-h Ulva exposure is suggested, because within $3 \mathrm{~h}$ the algae are able to remove most of the ammonia and the possible uptake of metals and absorption of organics are minimized or absent. Longer exposure can be taken into account for particularly ammonia-rich samples.

The results obtained with the pore water from site Q1 highlight that the actual sequences are not able to characterize all the toxicants present in the study area, so the procedures need improvements in order to resolve all the sources of toxicity. A first improvement could be gained by adding to the sequence the elution through an alternative SPE column able to remove pesticides and/or ionic organic contaminants too. This second elution should be performed in parallel with the usual $\mathrm{C}_{18}$ column and not as alternative, because literature experiences reported an increase of the toxicity was measured after elution (NFESC, 2003).

\section{Acknowledgments}

This work was granted by BIOMIT 2-Quicksilver project promoted by Consiglio Nazionale delle Ricerche-Centro Ricerche Interdipartimentale Biotecnologie Innovative (CNR-CRIBI). The authors were very grateful to Andrea Berton for sampling sediments.

\section{References}

ASTM, 2004. Standard Guide for Conducting Static Acute Toxicity Test Starting with Embryos of Four Species of Saltwater Bivalve Molluscs. E724-98, American Society for Testing and Materials.

His, E., Beiras, R., Seaman, M.N.L., 1999. The assessment of aquatic contamination; bioassays with bivalve larvae. Adv. Mar. Biol. 37, 1-178.

Ho, K.T., McKinney, R.A., Kuhn, A., Pelletier, M.C., Burgess, R., 1997. Identification of acute toxicants in New Bedford sediments. Environ. Toxicol. Chem. 16, 551-558.
Ho, K.T., Kuhn, A., Pelletier, M.C., Burgess, R.M., Helmstetter, A., 1999. Use of Ulva lactuca to distinguish $\mathrm{pH}$-dependent toxicants in marine waters and sediments. Environ. Toxicol. Chem. 18, 207-212.

Losso, C., Picone, M., Arizzi Novelli, A., Delaney, E., Ghetti, P.F., Volpi Ghirardini, A., 2007. Developing toxicity scores for embryotoxicity tests on elutriates with the sea urchin Paracentrotus lividus, the oyster Crassostrea gigas and the mussel Mytilus galloprovincialis. Arch. Environ. Contam. Toxicol. 53, 220-226.

Martin, M., Osborn, K.E., Billig, P., Glickstein, N., 1981. Toxicities of ten metals to Crassostrea gigas and Mytilus edulis embryos and Cancer magister larvae. Mar. Pollut. Bull. 12 (9), 305-308.

NFESC, 2003. Guide for Planning and Conducting Sediment Pore Water Toxicity Identification Evaluations (TIE) to Determine Causes of Acute Toxicity at Navy Aquatic Sites. Naval Facilities Engineering Service Center. Prepared by Science Applications International Corporation, Newport, RI 02840 UG-2052-ENV.

Picone, M., 2006. Impiego di una batteria di saggi ecotossicologici nel monitoraggio della qualità dei sedimenti della Laguna di Venezia. Ph.D. Thesis, Ca' Foscari University of Venice (in Italian).

Picone, M., Bergamin, M., Arizzi Novelli, A., Noventa, S., Delaney, E., Barbanti, A., Volpi Ghirardini, A., 2008. Evaluation of Corophium orientale as bioindicator for Venice-Lagoon: sensitivity assessment and toxicity-score proposal. Ecotoxicol. Environ. Saf. 70, 174-184.

Rice, D.L., 1984. A simple mass transport model for metal uptake by marine macroalgae growing at different rates. J. Exp. Mar. Biol. Ecol. 82, 175-182.

Rice, D.L., Lapointe, B.E., 1981. Experimental outdoor studies with Ulva fasciata Delile. II. Trace metal chemistry. J. Exp. Mar. Biol. Ecol. 54, 1-11.

Turetta, C., Cozzi, G., Barbante, C., Capodaglio, G., Cescon, P., 2004. Trace elements determination in seawater by ICP-SFMS coupled with a microflow nebulization/desolvation system. Anal. Bioanal. Chem. 380, 258-268.

USEPA, 1991. Methods for Aquatic Toxicity Identification Evaluations-Phase I Toxicity Characterization Procedures. EPA-600-6-91-003, US Environmental Protection Agency, Washington, DC.

USEPA, 1996. Marine Toxicity Identification Evaluation (TIE)-Phase I Guidance Document. EPA-600-R96-054, US Environmental Protection Agency, Washington, DC

USEPA, 2002. Short-term methods for estimate the chronic toxicity of effluents and receiving waters to marine and estuarine organisms. EPA 821/R-02/014, US Environmental Protection Agency, Washington, DC.

Volpi Ghirardini, A., Arizzi Novelli, A., 2001. A sperm-cell toxicity test procedure for the Mediterranean species Paracentrotus lividus (Echinodermata: Echinoidea). Environ. Technol. 22, 439-445.

Volpi Ghirardini, A., Arizzi Novelli, A., Tagliapietra, D., 2005a. Sediment toxicity assessment in the Lagoon of Venice (Italy) using Paracentrotus lividus (Echinodermata: Echinoidea) fertilization and embryo bioassays. Environ. Int. 31, 1065-1077.

Volpi Ghirardini, A, Losso, C., Arizzi Novelli, A., Baù, A., His, E., Ghetti, P. , 2005b. Mytilus galloprovincialis as bioindicator in embryotoxicity testing to evaluate sediment quality in the lagoon of Venice (Italy). Chem. Ecol. 21, 455-463. 